\title{
Study on the Content Validity of the Essential Assessment Items Required for Visiting Nurses to Service Users in Japan
}

\author{
Izumi Ueda ${ }^{1}$, Wakako Mizuguchi ${ }^{1}$, Masahiko Sasaki ${ }^{2} \&$ Madoka Yokoyama $^{1}$ \\ ${ }^{1}$ School of Health Sciences, Sapporo Medical University, Sapporo, Japan \\ ${ }^{2}$ School of Nursing and Nutrition, Tenshi College, Sapporo, Japan \\ Correspondence: Izumi Ueda, Department of Nursing, School of Health Sciences, Sapporo Medical University, \\ South1 West 17, Chuo-ku, Sapporo, 060-8556 Japan. Tel: 81-11-611-2111 Ext 28620.
}

Received: February 15, 2017

Accepted: March 7, 2017

Online Published: April 6, 2017

doi:10.20849/ijsn.v2i1.137

URL: https://doi.org/10.20849/ijsn.v2i1.137

This study is supported by 2015 year The Yuumi Memorial Foundation for Home Health Care grants.

\begin{abstract}
Objective: We examined the content validity of the essential assessment items for service user recognized by visiting nurses. Methods: Anonymous self-reported questionnaire were sent by mail two times to nurses experts. The questionnaire comprised assessment items related to five major categories, and fist survey asked by 82 items, second survey asked by 83 items with 4-point scale. We analyzed the data using weighed average. Results: The final assessment items were 83. Conclusion: In the visiting nursing practice field, we think of easier ways to common view of assessment records all over the country and improvement of quality of visiting nursing practice by utilizing of assessment items of this study with considering of degree of priority.
\end{abstract}

Keywords: content validity, essential assessment items, visiting nurses, service users

\section{Introduction}

In Japan, the government is promoting the home health care. The visiting nursing service in the home health care is increasing expectation. The visiting nursing service in Japan is carrying out based on the long-term care insurance system and a medical insurance system. There are about 8200 visiting nursing service station in Japan, go on increasing (2015.4). The organizations of established station are variety of type. There is much the small scale company in Japan. The researchers suggested that nursing assessment not view on nurses carry out visiting nurse service, and it is not clear decision of nursing diagnosis or nursing care through nursing process. (Hirose, 2011)

In each visiting nursing station perpetrate nursing records by own and created record styles are not uniform. The methods of share the assessment contents not established. There is necessary for development assessment tools essential for the nursing process of visiting nurses practices.

In japan, as one field in nursing various fields, area of home health care nursing joined the nursing education curriculum since 1997. Supported by national nursing education institutions survey, $74 \%$ of the teachers were used existing nursing theory and nursing models (Nakamura, Kinoshita, 2009). And they added viewpoint of home health care in existing models. They used existing nursing theory such as Henderson, Gordon, ICF, etc. however, were crossing a wide range of. As one reason of wide variety, home health care nursing models and theories are very few. In other words, there is no nursing model for home health care nursing in Japan. It is problem which now confronts us. And home health care nursing model is not developed yet in japan. On the other hand, from 2010, the study of visit nursing assessment by IT system has started. It is planning to visualize the nursing assessment by the flow chart. However, I think that nurses thinking process not remain in the way is problem. How they decided medical treatment or nursing diagnosis based on any symptoms and signs? As the process of the nursing diagnosis is not noted on nurse records, in time of selected only contents of a nursing care plan, nursing diagnosis, we are apprehensive about the assessment skills deterioration of nurses.

As trend of abroad, there are a number of assessment tools for evaluation of the quality of home visiting nursing. Also, there are many agencies and type of job for home visiting in the United States, their role divide into detail 
contents. Specialist nurses has own field such as diabetes, wound care, etc. Thus, their assessment contents specialized, too. The assessment contents or items cannot be reflected in the visiting nursing of our country. The assessment tool has reliability and validity in japan is not yet established. The final goal of this study is development of assessment tool of visiting nursing in Japan. The goal of this study is clarity assessment items which a necessary and indispensable utilizing at visiting nursing field. This assessment items are minimum requirements to apply all user of home visiting nursing services.

\section{Method}

\subsection{Collection of Item}

We examined construct or conceptual framework containing assessment items and indicators based on literature review and previous studies. First, we collected assessment items through domestic home visiting nursing literature and books. However, because of different foreign system, abroad literature ultimately excluded. After, limited to only domestic literature and books, we collected all assessment items. We organized main-categories, medium and small items by contents analysis. We dealt unless the assessment indicators, but only the items. As a result, 5 main-categories, created the assessment items arranged 20 medium- items, and 82 small items.

\subsection{Survey by Nurse Experts for Careful Selection Items}

An examination for the content validity of we collected items carried out by two times of expert's survey.

\subsubsection{Subject and Survey Period of This Study}

Subject of this study was twenty of university teachers who have experience of scale development research and visiting nurses who rich in practice experience.

This survey period was 2weeks in August on 2016 year. After first time survey, question items revised based on analysis of the first results. After one month of first survey, second survey carried out.

\subsubsection{Methods of Survey}

Anonymous self-reported questionnaire were sent by mail. The contents of questionnaire were the attribute of subject and question for content validity of collected items. We asked the validity of content to main-category, medium-item and item by 4-point scale. And each of medium-items set free reported space for ask view such as discontent or luck of expression or exemplify.

\subsubsection{Data Analysis}

This exclusion of criterion was response rate of below $90 \%$. But, there was no exclude questionnaire. Missing answer and double answer were handled as deficit value. We analyzed the data using weighed average. The weighed of answers were appropriate $=2$, somewhat appropriate $=1$, somewhat inappropriate $=-1$, inappropriate $=-2$. The criterion of appropriate items was above 1.5 which shows fact of selected appropriate above half the questionnaire.

\subsection{Ethical Considerations}

We explained object of this study, methods, liberty of participate, personal information protection by mailed document. And consent to research collaboration judged by return questionnaires. We obtained approval to conduct the study from the Ethics Committee of Sapporo Medical University (27-2-62.approval number).

\section{Results}

In distributed questionnaires, response rate of first survey was $70.0 \%$, second time was $60.0 \%$. There was no invalid in all questionnaires. The main-categories are expressed with single quotation marks (" '), the medium items with double quotation marks (“"), and items are with square brackets ([ ]).

\subsection{Attribution of Subject}

Attribution of subject on first survey were 1 male and 13 female, and average of nurse experience was 12.38 years $(\mathrm{SD}=11.62)$, average of visiting nurse experience was 8.91 years $(\mathrm{SD}=8.08)$. Attribution of subject on second survey were 1 male and 11 female, and average of nurse experience was 17.0years ( $\mathrm{SD}=14.12)$, average of visiting nurse experience was 8.91 years $(\mathrm{SD}=8.08)$.

\subsection{Experts Survey for Careful Selection Items-First Time}

\subsubsection{The Content Validity of Items}

The results of this study are shown in Tables 1-5. The items of below 1.5 not reached the criteria of appropriate were 6 of 18 items in Table 1. Their items were [others] - "housing environment", and [topography], [road 
condition], [transportation], [neighborhood facilities], [natural environment] - "community environment" on 'basic attribution' in Table 1. The items of below 1.5 was 1 of 16 items in Table 3 . The item was [belonging group] - "society, social exchange" on 'psychology social function' in Table 3.

Their items were 4 of 19 items in Table 4. Their items were [family's development stage] - "development stage and task of family", [rules in family] - "rules in family and influential relation" on "the condition of family and caregiver' in Table 4.

All of items of utilization of social resources in Table 5 were value of above 1.5.

\subsubsection{Revision of Items}

Based on opinion or proposal that expression of the items difficult to understand and items needs to be modified, the 2 items were deleted in Table 2. And in Table 2 added [character] in "mental function".

In Table 3, [lifestyle] of "how to lives" changed in [habit of life], and [the interest in news of social] of "sociality, social exchange", changed in [social situation]. In the Table 4, the items in "family as caregiver" added [existence of main-caregiver] and [health of caregiver].

\subsection{Experts Survey for Careful Selection Items-Second Time}

In Table 1, their items of below 1.5 not reached the criteria of appropriate were 5items. But their items just remained. Except their items, other items were all above 1.5. The average of each of main-categories was $1=1.59$, $2=1.90,3=1.83,4=1.83,5=1.78$.

Table 1. Basic information

\begin{tabular}{|c|c|c|c|c|c|c|}
\hline Category & First & Second & Sub-category & Modification & First & Second \\
\hline $\begin{array}{l}\text { Family } \\
\text { members }\end{array}$ & 1 & 1 & & & 1.71 & 2.00 \\
\hline $\begin{array}{l}\text { Required } \\
\text { information } \\
\text { including postal } \\
\text { address }\end{array}$ & & 2 & & Added & - & 1.92 \\
\hline Occupation & 2 & 3 & & & 1.64 & 1.58 \\
\hline $\begin{array}{l}\text { Health } \\
\text { insurance }\end{array}$ & 3 & 4 & & & 1.71 & 1.58 \\
\hline $\begin{array}{l}\text { Economic } \\
\text { conditions }\end{array}$ & 4 & 5 & & & 1.79 & 1.92 \\
\hline \multirow[t]{7}{*}{$\begin{array}{l}\text { Housing } \\
\text { environment }\end{array}$} & 5 & 6 & Housing type & & 1.86 & 1.75 \\
\hline & 6 & 7 & Floor plan & & 1.71 & 1.50 \\
\hline & 7 & 8 & Condition of the floor & & 1.43 & 1.67 \\
\hline & 8 & 9 & Ventilation and room temperature & & 1.79 & 1.67 \\
\hline & 9 & 10 & Cleaning & & 1.64 & 1.75 \\
\hline & 10 & & Living environment to be improved & Deleted & 1.50 & \\
\hline & 11 & & Utilization and need for special equipment & Deleted & 1.64 & \\
\hline \multirow[t]{5}{*}{$\begin{array}{l}\text { Community } \\
\text { environment }\end{array}$} & 12 & 11 & Topography & & 0.86 & 1.08 \\
\hline & 13 & 12 & Road condition & & 0.86 & 1.17 \\
\hline & 14 & 13 & Transportation & & 1.21 & 1.42 \\
\hline & 15 & 14 & Neighborhood facilities & & 1.21 & 1.00 \\
\hline & 16 & 15 & Natural environment & & 0.36 & 1.00 \\
\hline
\end{tabular}




\begin{tabular}{|c|c|c|c|c|c|c|}
\hline \multirow[t]{2}{*}{$\begin{array}{l}\text { Complaints and } \\
\text { requests }\end{array}$} & 17 & 16 & Request from patient and family & & 1.71 & 2.00 \\
\hline & & 17 & Request for care & Added & - & 2.00 \\
\hline
\end{tabular}

Table 2. Health status of patient

\begin{tabular}{|c|c|c|c|c|c|c|}
\hline Category & First & Second & Sub-category & Modification & First & Second \\
\hline \multirow[t]{4}{*}{$\begin{array}{l}\text { Medical } \\
\text { concerns }\end{array}$} & 18 & 18 & Medical history & & 1.93 & 2.00 \\
\hline & 19 & 19 & Present illness & & 2.00 & 2.00 \\
\hline & 20 & 20 & Home doctor & & 2.00 & 2.00 \\
\hline & 21 & 21 & Access to medical treatment & & 1.64 & 1.92 \\
\hline \multirow[t]{16}{*}{$\begin{array}{l}\text { Physical } \\
\text { functioning }\end{array}$} & 22 & 22 & Vital sign & & 2.00 & 2.00 \\
\hline & 23 & 23 & Height and weight & & 1.71 & 1.92 \\
\hline & 24 & 24 & Growth and development & & 1.50 & 1.83 \\
\hline & 25 & 25 & Nutrition & & 1.79 & 2.00 \\
\hline & 26 & 26 & Allergy & & 1.71 & 1.83 \\
\hline & 27 & 27 & Teeth and mouth & & 1.71 & 1.92 \\
\hline & 28 & 28 & Voiding & & 2.00 & 1.92 \\
\hline & 29 & 29 & Skin-sanitation & & 1.86 & 1.92 \\
\hline & 30 & 30 & Pain & & 2.00 & 1.92 \\
\hline & 31 & 31 & Paralysis and contracture & & 2.00 & 1.92 \\
\hline & 32 & 32 & Consciousness & & 1.71 & 1.92 \\
\hline & 33 & 33 & Sensory functions & & 1.71 & 1.83 \\
\hline & 34 & & Other & Deleted & 1.43 & - \\
\hline & 35 & 34 & $\mathrm{ADL}$ & & 1.93 & 2.00 \\
\hline & 36 & & Problem details & Deleted & 1.57 & - \\
\hline & 37 & & Terminal & Deleted & 1.64 & - \\
\hline \multirow[t]{8}{*}{$\begin{array}{l}\text { Psychological } \\
\text { functioning }\end{array}$} & 38 & 35 & Appearance & & 1.64 & 1.67 \\
\hline & 39 & 36 & Mental state & & 1.71 & 2.00 \\
\hline & 40 & 37 & Cognitive functions & & 1.86 & 1.92 \\
\hline & 41 & 38 & Memory and attentiveness & & 1.79 & 1.83 \\
\hline & 42 & 39 & Oriented & & 1.86 & 1.83 \\
\hline & 43 & 40 & Perception and conception & & 1.36 & 1.92 \\
\hline & & 41 & Personality & Added & - & 1.75 \\
\hline & 44 & 42 & Coping & & 1.57 & 1.67 \\
\hline
\end{tabular}


Table 3. Patient psychosocial functioning

\begin{tabular}{|c|c|c|c|c|c|c|}
\hline Category & First & Second & Sub-category & Modification & First & Second \\
\hline \multirow[t]{4}{*}{ Living } & 45 & 43 & Activity & & 1.57 & 1.92 \\
\hline & 46 & 44 & Lifestyle $\rightarrow$ Life habits & Expressions & 1.86 & 2.00 \\
\hline & 47 & 45 & Willingness to live & & 1.64 & 1.83 \\
\hline & 48 & 46 & Awareness of health and health concerns & & 1.57 & 1.92 \\
\hline \multirow[t]{6}{*}{$\begin{array}{l}\text { Sociability and } \\
\text { social } \\
\text { exchanges }\end{array}$} & 49 & 47 & $\begin{array}{l}\text { Opportunities for outings and the } \\
\text { frequency }\end{array}$ & & 1.64 & 1.83 \\
\hline & 50 & 48 & Exchanges with neighbors and friends & & 1.64 & 1.83 \\
\hline & 51 & 49 & Social role & & 1.64 & 1.67 \\
\hline & 52 & 50 & Group affiliation & & 0.86 & 1.50 \\
\hline & 53 & 51 & Interest in events $\rightarrow$ Interest in society & Expressions & 1.36 & 1.50 \\
\hline & 54 & 52 & Communication ability & & 1.71 & 1.92 \\
\hline \multirow[t]{3}{*}{$\begin{array}{l}\text { Will to choose } \\
\text { life at home }\end{array}$} & 55 & 53 & Will to recuperate at home & & 2.00 & 2.00 \\
\hline & 56 & 54 & Perception of diseases & & 1.93 & 2.00 \\
\hline & & 55 & Pleasure in life & Added & - & 1.92 \\
\hline \multirow[t]{3}{*}{$\begin{array}{l}\text { Feelings } \\
\text { towards the } \\
\text { family }\end{array}$} & 57 & 56 & Feelings towards family members & & 1.86 & 1.92 \\
\hline & 58 & 57 & $\begin{array}{l}\text { Awareness of being a member in the } \\
\text { family }\end{array}$ & & 1.86 & 1.67 \\
\hline & 59 & 58 & Thoughts on nursing care & & 1.86 & 1.92 \\
\hline
\end{tabular}

Table 4. Conditions of family and caregivers

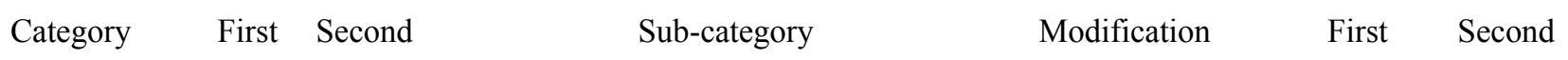

\begin{tabular}{lcclrl}
\hline $\begin{array}{l}\text { Stages of family } \\
\text { development } \\
\text { and family } \\
\text { problems }\end{array}$ & 60 & 59 & Development stage of family members & 1.50 & 1.58 \\
& 61 & 60 & Development stage of family & 1.36 & 1.67 \\
\hline $\begin{array}{l}\text { Relationship } \\
\text { among family } \\
\text { members }\end{array}$ & 62 & 61 & Communication in the family & 1.79 & 1.92 \\
& 63 & 62 & Attachment and repelling & 1.57 & 1.92 \\
\hline $\begin{array}{l}\text { Relationship } \\
\text { with relatives } \\
\text { and neighbors }\end{array}$ & 64 & 63 & & 1.71 & 1.67 \\
\hline $\begin{array}{l}\text { Family role and } \\
\text { power relations }\end{array}$ & 65 & 64 & Role of family members & 1.86 & 1.83 \\
& 66 & 65 & Role adjustment of family members & 1.64 & 1.92 \\
& 67 & 66 & Family rules & 1.36 & 1.75 \\
& 68 & 67 & Decision maker & 1.86 & 1.92 \\
\hline
\end{tabular}


Coping methods

and problem-solving

68 Stress suffered by family members

ability of the

family

\begin{tabular}{llllll} 
& 70 & 69 & Stress coping and adaptation in the past & 1.79 & 1.75 \\
& 71 & 70 & Present stress coping and adaptation & 1.71 & 1.83 \\
\hline $\begin{array}{l}\text { Family sense of } \\
\text { values }\end{array}$ & 72 & 71 & Sense of values of each family member & 1.86 & 1.75 \\
& 73 & 72 & Sense of values of the family & 1.86 & 1.83 \\
\hline $\begin{array}{l}\text { Family as the } \\
\text { caregiver }\end{array}$ & 73 & Having a main caregiver & Added & - & 2.00 \\
& 74 & Health of caregiver & - & 1.92 \\
& 74 & $\begin{array}{l}\text { Daily and weekly schedule of the } \\
\text { caregiver }\end{array}$ & 1.86 & 1.92 \\
& 76 & 76 & Knowledge and skills in the care & 1.86 & 1.92 \\
& 76 & 77 & Motivation to provide care and will to continue & 1.86 & 1.83 \\
\hline & & & Average & 1.83
\end{tabular}

Table 5. Utilization of social resources

\begin{tabular}{lrrrrr}
\multicolumn{1}{c}{ Category } & First & Second & \multicolumn{1}{c}{ Sub-category } & Fodification & Second \\
\hline $\begin{array}{l}\text { State of using } \\
\text { social resources }\end{array}$ & 77 & 78 & Services covered by the Long-term Care Insurance & 1.93 & 2.00 \\
& 78 & 79 & Services outside the Long-term Care Insurance & 1.93 & 1.92 \\
& 79 & 80 & Satisfaction & 1.79 & 1.83 \\
& 80 & 81 & Support from neighbors and volunteers & 1.71 & 1.67 \\
& 81 & 82 & Support from the community and local welfare & 1.50 & 1.58 \\
& 82 & 83 & Unused service needs & 1.60 & 1.67 \\
\hline
\end{tabular}

Cutoff value for items to be considered appropriate $=1.5$ or higher.

Items below the cutoff value

\section{Discussion}

The essential assessment items required for patients used visiting nurse services were 5 main-categories, 23 of medium items, 83 of small items.

\subsection{Basic Attribution}

Basic attribution such as family members and housing environment is an essential item. However, as a result of this data, items of community environment were lower validity and were not considered to essential items.

Recently, it is reflecting that area of home health care nursing joined the nursing education curriculum, and visiting nursing services has been increasing (Ministry of health, labor and welfare, 2011). Nurses has long-time practice experience did not started subjects of home health care nursing in nursing education they received. They have experienced education and practice centered on assessment of personal perspective. From now on, not only assessment of personal life, but also community assessment such as the climate, disaster, nature, point of view that how community live are necessary. Their items were left just as. 


\subsection{Health of Physical and Psychological}

Health of physical and psychological of patients was appropriate for items as a minimum. All items could be considered requite as base assessment. Items of symptoms by the disease or syndrome from these items are should be focused assessment (Yamauchi et al., 2009).

\subsection{Psychological Social Function}

Item of belonging groups in psychological social function of patients was lower validity. But we think it is necessary item and to be left behind. The belonging group mean whether belonging to the some groups, social status, job title (Ueda et al., 2015). Expression should be devised.

\subsection{Condition of the Family and Caregiver}

The stage of family development, rules in family was lower the appropriate degree. However, their items is listed as a family assessment from the family nursing theory by Watanabe et al (Ueno et al. 2014). As a result in remained the second survey were kept appropriate degrees. The items about the family as a caregiver, added to existence of a main caregiver, health of caregiver. The home care is promoted in Japan, the service of long-term care insurance system started, but in the present circumstances, there are many cases rely on family caregivers. Their items are essential item that should get hold of.

\subsection{Use of Social Resources}

This item rated validity highly on both surveys. In Japan, long-term care insurance act has been enforced, and as one of the in-home care service placed visiting nursing services. Understand of use and satisfaction about other service of long-term care insurance act services is essential content.

\section{Conclusions}

From the results of this study, 83 assessment items which a necessary and indispensable utilizing at visiting nursing field were clarified. Because the assessment tool has reliability and validity in japan is not yet established, these results will be useful in future at visiting nursing field.

In the visiting nursing practice field, we think of easier ways to common view of assessment records all over the country and improvement of quality of visiting nursing practice by utilizing of assessment items of this study with considering of degree of priority.

\section{References}

Hirose, J. (2011). Houmonkango assessment-protocol beteran kangoshi no atama no naka wo kashika site kyouyuu suru. Houmonkango to kaig, 16(5), 384-391.

Ministry of Health, Labor and Welfare. (2007). Kangokisokyouikunozyuuzitunikansuruhoukokusyo.1-45. Retrieved December 2016, from http://www.mhlw.go.jp/shingi/2007/04/dl/s0420-13.pdf

Nakamura, Y., \& Kinoshita, A. (2009). Research on teaching nursing process for home care nursing at nursing schools in Japan. The Japanese Red Cross Akita College of Nursing and the Japanese Red Cross Junior College of Akita, 14, 35-41.

The national association for home-visit nursing care. (2016). The survey of Home visit nursing stations in Japan. Retrieved December 2016, from https://www.zenhokan.or.jp/pdf/new/h28-research.pdf

Ueda, I. comp. (2015). Zaitakukangokateiensyuu-assessment, tougou, kangokeikaku kara zisshi, hyouka he-. Quality-care, 1-31.

Ueno, M., Nakamura, J. comp., \& Watanabe, Y. (2014). Kazokukango wo kiban to shita zaitakukangoron I gairon hen dai3han. Japanese Nursing Association Publishing Company, 125, 173-179.

Yamauchi, T., \& Okamoto, S. (Eds.) (2009). Seimei-seikatsu no ryoumen kara toraeru houmonkango assessment protocol. chuohoki, 62-63.

Yamauchi, T., \& Okamoto, S. (Eds.) (2009). Seimei-seikatsu no ryoumen kara toraeru houmonkango assessment protocol. chuohoki, 72-81.

\section{Copyrights}

Copyright for this article is retained by the author(s), with first publication rights granted to the journal.

This is an open-access article distributed under the terms and conditions of the Creative Commons Attribution license (http://creativecommons.org/licenses/by/4.0/). 